\title{
"Stent" auto-expansível nas dissecções da aorta tipo B
}

\author{
Wagner Michael PEREIRA*, José Dario FROTA FILHO* ${ }^{*}$ Marcela SALES*, Nilton DELATORRE*, \\ Paulo E. LEÃES* ${ }^{*}$ Celso BLACHER* ${ }^{*}$ Eraldo LÚCIO*, Patrícia Q. PEREIRA***, \\ Pierre G. SILVEIRA**, Telmo P. BONAMIGO*, Fernando A. LUCCHESE*
}

RBCCV 44205-462

\begin{abstract}
Pereira W M, Frota Filho J D, Sales M, Delatorre N, Leães P E, Blacher C, Lúcio E, Pereira P Q, Silveira P G, Bonamigo T P, Lucchese F A - "Stent" auto-expansível nas dissecções da aorta tipo B. Rev Bras Cir Cardiovasc 1999; 14 (3): 207-14
\end{abstract}

RESUMO: O tratamento clínico das dissecções agudas da aorta do tipo B tem mortalidade em torno de $25 \%$ menor que a mortalidade cirúrgica. O tratamento cirúrgico das dissecções crônicas também produz uma morbidade e mortalidade elevadas. A utilização de "stents"auto-expansíveis endovasculares pode ser uma nova alternativa no tratamento destas lesões. De abril a dezembro de 1998 foram implantados 15 "stents" endovasculares, 10 em dissecções agudas e 5 em crônicas. A idade dos pacientes variou entre 48 e 75 anos (média $=60,53 \pm 9,73$ anos) com $66,6 \%$ do sexo masculino. Os pacientes foram submetidos à esternotomia mediana, circulação extracorpórea (CEC) com hipotermia profunda $\left(18^{\circ}-20^{\circ} \mathrm{C}\right)$, parada circulatória total $(P C T)$ e perfusão cerebral retrógrada (PCR). A aorta transversa foi incisada e implantado o "stent" na aorta descendente sob auxílio de aortoscopia. Foram analisados os tempos de CEC, pinçamento aórtico, PCT, PCR, reaquecimento, ventilação mecânica, internação, sangramento trans e pós-operatório, reposição sangüínea, gasometria, curva de eventos e sobrevida. A mortalidade hospitalar (30 dias) foi de 6,6\%; 2 pacientes foram reoperados com 3 e 6 meses após a operação com dissecção da aorta ascendente e aneurisma roto distal ao "stent". Quatorze vêm sendo acompanhados com 1 a $8 \mathrm{~m}$ de evolução, sendo que $85,7 \%$ estão livres de eventos e curva de sobrevida de 93,1\%(240 dias). Concluímos que o implante de "stent"intraluminais auto-expansíveis apresentou mortalidade menor na fase aguda da doença (6,6\%) comparada à nossa experiência anterior com o tratamento clínico (30\%). Apesar da amostra ser pequena, o procedimento parece ser promissor e necessita mais acompanhamento.

DESCRITORES: Aneurisma aórtico, cirurgia. Aneurisma dissecante, cirurgia. Contenedores.

\section{INTRODUÇÃO}

A indicação cirúrgica das dissecções agudas da aorta tipo A (Stanford) está bem estabelecida e existe quase unanimidade no procedimento logo que o diagnóstico for confirmado. No entanto, nas dissecções do tipo B, aorta descendente, ainda persiste a discussão entre o tratamento clínico e o cirúrgico. A controvérsia iniciou com o clássico trabalho de WHEAT et al. (1), recomendando o tratamento clíni- co na comparação com a operação deixando esta última para os casos complicados (isquemia abdominal ou rotura). À época, a operação das dissecções incluía a fenestração na aorta abdominal ${ }^{(2,3)}$, a tromboexclusão ${ }^{(4)}$ e a interposição de enxertos $(5,6)$, todas com morbidade e mortalidade mais elevadas que $\mathrm{o}$ tratamento medicamentoso. Porém, o tratamento conservador não impede o crescimento da falsa luz nem a isquemia de órgãos abdominais e

Trabalho realizado no Hospital São Francisco de Cardiologia e Transplantes, Porto Alegre, RS, Brasil.

Apresentado ao 26ํㅡㄹ Congresso Nacional de Cirurgia Cardíaca. Fortaleza, CE, 8 a10 de abril , 1999.

* Do Hospital São Francisco de Cardiologia e Transplantes de Porto Alegre.

** Do Departamento de Clínica Cirúrgica da Universidade Federal de Santa Catarina, Florianópolis, SC.

*** Da Universidade Luterana do Brasil, Ulbra, Canoas, RS.

Endereço para correspondência: Wagner M. Pereira. Av. Jacuí 450/1902, Porto Alegre, RS, Brasil. CEP 90810-150. Tel. (051) 2498042. e-mail: wagnermp@pro.via-rs.com.br 
Pereira W M, Frota Filho J D, Sales M, Delatorre N, Leães P E, Blacher C, Lúcio E, Pereira P Q, Silveira P G, Bonamigo T P, Lucchese F A - "Stent" auto-expansível nas dissecções da aorta tipo B.

Rev Bras Cir Cardiovasc 1999; 14 (3): 207-14.

membros inferiores levando a uma mortalidade em 5 anos de $65 \%(7,8)$. Houve, nos anos seguintes, o desenvolvimento de novas técnicas cirúrgicas, como a de BORST et al.(9) "tromba de elefante", a cola biológica ${ }^{(10)}$,as próteses intraluminais sem sutura ${ }^{(11-13)}$ e, por fim, as próteses intraluminais percutâneas ${ }^{(14)}$ expandidas por balão(15) e auto-expansíveis( ${ }^{(16)}$.

O objetivo deste trabalho é o relato da experiência do Hospital São Francisco com a utilização dos "stents" auto-expansíveis nas dissecções da aorta do tipo B, mostrando seu método nos implantes, sua reprodutibilidade e complicações decorrentes da curva de aprendizado. No estado atual das operações acreditamos que o tratamento precoce das dissecções agudas evita a expansão da falsa luz, que aparece na fase crônica da doença, com mortalidade menor que o tratamento conservador.

\section{CASUÍSTICA E MÉTODOS}

No decorrer do ano de 1998 foram submetidos a operações da aorta 45 pacientes, 22 com aneurisma da aorta e 23 com dissecções agudas. De abril a dezembro de 1998 foram implantados 15 "stents"(65,2\% das dissecções) auto-expansíveis na aorta descendente proximal nas dissecções agudas e crônicas da aorta. Todos foram submetidos a esternotomia mediana com CEC por canulação femoral e hipotermia profunda com PCT $\left(18^{\circ}-20^{\circ} \mathrm{C}\right)$ e PCR. A aorta transversa foi incisada e os orifícios de rotura vistos com auxílio de visão endoscópica. O diagnóstico foi estabelecido isoladamente ou em conjunto com: tomografia computadorizada em $73,3 \%(11 / 15)$ dos casos, ecocardiografia transesofágica em $86,6 \%(13 / 15)$ e cineangiocoronariografia em 86,6\% (13/15). Foram diagnosticadas 10 (66,6\%) dissecções agudas e 5 (33,3\%) crônicas; as idades variaram de 45 a 75 anos (média $=60,5 \pm 9,7$ ) e $66,6 \%$ eram do sexo masculino. A classe funcional segundo a classificação da NYHA é representada na Figura 1. Todos os pacientes eram hipertensos prévios e os fatores de risco associados à lesão podem ser vistos na Tabela 1; a etiologia degenerativa es-

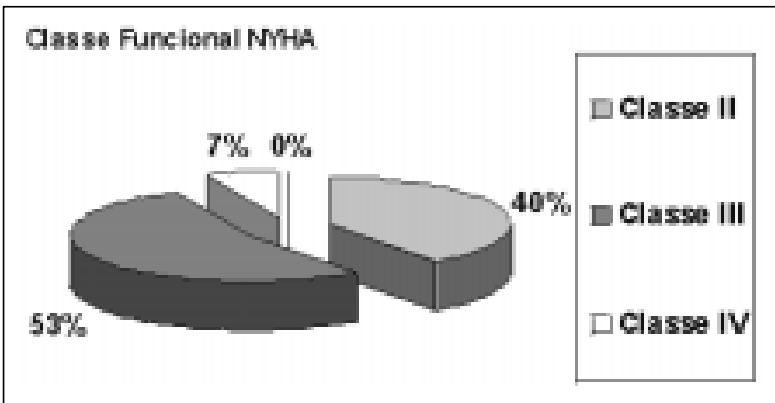

Fig. 1
TABELA 1

FATORES DE RISCO ASSOCIADOS

\begin{tabular}{ll}
\hline Tabagismo & $73,3 \%(11 / 15)$ \\
Hipertensão & $100 \%$ \\
Dilipidemias & $40,0 \%(6 / 15)$ \\
Insuficiência Renal Aguda & $13,3 \%(2 / 15)$ \\
Diabetes & $20,0 \%(3 / 15)$ \\
\hline
\end{tabular}

teve presente em $66,6 \%(10 / 15)$ e aterosclerótica em 33,3\% (5/15). Os diâmetros nas dissecções crônicas variaram entre $57,0 \mathrm{~mm}$ a $78,0 \mathrm{~mm}$ (média = $64,33 \pm 07,54 \mathrm{~mm})$

Os pacientes foram monitorizados com eletrocardiograma (ECG) em duas derivações (D2 e V5), oximetria de pulso, medida de pressão arterial média (PAM) e pressão venosa central (PVC), capnografia, temperaturas nasofaríngea e periférica, medida de tempo de coagulação ativado (TCA), gasometrias seriadas para controle de ventilação, equilíbrio ácidobásico e medida de diurese. São realizadas punções de 2 veias periféricas e punção de artéria radial esquerda. A indução da anestesia é feita com Midazolan 100 a $200 \mathrm{mcg} / \mathrm{kg}$, Fentanil 5 a $10 \mathrm{mcg} /$ $\mathrm{kg}$ e Pancurônio 0,08 a 0,1 mg/kg; a manutenção de anestesia é obtida com administração contínua de $2 \mathrm{mcg} / \mathrm{kg} / \mathrm{min}$ de Midazolan e $0,16 \mathrm{mcg} / \mathrm{kg} / \mathrm{min}$ de Fentanil. Após início da CEC e até o final do procedimento diminuem-se as doses para metade ou menos, de acordo com sinais de profundidade anestésica. A ventilação mecânica é realizada visando manter $\mathrm{PACO}_{2}$ entre 30 e $35 \mathrm{mmHg}$. Após intubação orotraqueal (IOT) realiza-se punção de veia central para medida de PVC ou pressão arterial pulmonar (PAP) e posiciona-se um Intracath $19 \mathrm{G}$ via ascendente na veia jugular interna direita até alcançar o bulbo jugular para medida de saturação venosa pré parada circulatória ( $P C)$ e para medida da pressão da PCR durante a parada circulatória. Administra-se previamente à indução anestésica o antibiótico (Cefazolina) de acordo com a rotina do Serviço, Dexametasona na dose de $10 \mathrm{mg}$ após a indução anestésica e $10 \mathrm{mg}$ antes da parada circulatória. A anticoagulação é realizada com heparina $5 \mathrm{mg} / \mathrm{kg}$, previamente às canulações arterial e venosas e repetida de $1 / 1$ hora na dose de $1 \mathrm{mg} / \mathrm{kg}$. A parada circulatória é estabelecida após obter-se temperatura nasofaríngea entre $18^{\circ}-20^{\circ} \mathrm{C}$ e após administração de $7 \mathrm{mg} / \mathrm{kg}$ de Thiopental, $1 \mathrm{mg} / \mathrm{kg}$ de heparina (se necessário) e administração da segunda dose de corticóide. O esfriamento e aquecimento levam de 3 a 5 minutos para cada grau de temperatura. Interrompe-se a administração de drogas intravenosas contínuas e inicia-se PCR com fluxo de $300 \mathrm{ml} / \mathrm{min}$. Mantém-se pressão no bulbo da jugular abaixo de $25 \mathrm{mmHg}$, regulando-se o fluxo de PCR ou administrando-se nitroprussiato de sódio (NPS). Ao final da parada 
Pereira W M, Frota Filho J D, Sales M, Delatorre N, Leães P E, Blacher C, Lúcio E, Pereira P Q, Silveira P G, Bonamigo T P, Lucchese F A - "Stent" auto-expansível nas dissecções da aorta tipo B.

Rev Bras Cir Cardiovasc 1999; 14 (3): 207-14.

circulatória administra-se novamente Thiopental na dose de $3 \mathrm{mg} / \mathrm{kg}$, reiniciam-se as drogas intravenosas, enquanto lentamente aquece-se o paciente até a temperatura nasofaríngea de $36^{\circ}-37^{\circ} \mathrm{C}$. A anticoagulação é revertida, após a saída de CEC e retirada das cânulas venosas e arterial com Protamina até $1 \mathrm{mg}$ para cada $\mathrm{mg}$ de heparina. Administram-se cristalóides no volume de $7 \mathrm{ml} / \mathrm{kg} /$ hora. A administração de sangue é regulada por dados hemodinâmicos e por medidas de hematócrito e hemoglobina. Retiram-se $500 \mathrm{ml}$ de sangue na chegada do paciente à sala, quando o hematócrito assim o permitir, realizando-se hemodiluição normovolêmica e reinfundindo este sangue após a administração da Protamina e na ausência de sangramento cirúrgico. Se persistir sangramento não cirúrgico após a administração da Protamina realiza-se o coagulograma e administram-se hemoderivados de acordo com o seu resultado.

Os procedimentos cirúrgicos foram os seguin-

\section{Monitorização}

Biomonitor 7 Bese com ECG de 7 derivações, com PNI, 2 canais de pressão, 2 canais de temperatura, canal para débito cardíaco e 2 monitores.

Respirador

Modelo 676 plus K.Takaoka com Rotâmetro 1815 eletrônico, com ar comprimido,óxido nitroso e oxigênio $20^{\circ} \mathrm{C} 101 \mathrm{kpa}$, Dilumatic vaporizado, Modular 1400 sistema Pinomatic.

Oxímetro

OSM $^{\mathrm{TM}}$ Hemoximeter-Radiometer, Copenhagen - Denmark com $\mathrm{Hb}, \mathrm{Hbo2}$ sat, $\mathrm{HbCo}$, Met $\mathrm{Hb}$, O2ct.

Bombas de Infusão

Nikkiso Com. LTDA. modelo PFA-05 e modelo PSK-01.

Oximetro de Pulso

Ohmeda Biox 3700, BOC Group Inc.

Desfibrilador

Code Master XE da Hewlett Packard.

Colchão Térmico

Medi-Therm modelo MTA - 4700, Gaymar Industries, Inc, New York Máquina de CEC

Sarns ${ }^{\mathrm{TM}} 8000$ com 5 roletes, Safety monitor $3 \mathrm{M}$, arterial monitor $3 \mathrm{M}$, cardioplegia monitor $3 \mathrm{M}$, Sarns $^{\mathrm{TM}}$ Occluder, misturador Sechrist. Oxigenadores

DMG 3000/2 membrana Hollow-Fiber com shunt veno-arterial

Braile Oxigenador membrana adulto MRX cq14 3000ml, Braile Biomédica.

Gasometrias na sala de cirurgia

i-STAT ${ }^{\circledR}$ Portable Clinical Analyser, i-STAT Corporation USA

Capnógrafo

4700 Oxicap Ohmeda, BOC group Incorporation USA.

Eletrocautério

Valleylab Pfiser force 2 eletrosurgical generator, Pfiser

Swang-Ganz ${ }^{\circledR}$ Baxter modelo $131 \mathrm{HF} 7$ thermodiluition catheter, introdutor Intro-Flex modelo I 300F85 Baxter, Baxter Healthcare Corporation, USA

Vídeo

Olympus OTV-S4, Olympus XLS, Ótica A525530 Germany, Monito

Sony 80 - Trinitron Color Super fine pitch, modelo PVM-1343MD

Hemoconcentrador

Haemonetics ${ }^{\circledR}$ Cell Saver ${ }^{\circledR}$ Plus, Haemonetics Corporation, USA tes: implante de "stent" isolado 33,3\%(5/15), "stent"+ fechamento de orifício de entrada 13,3\%(2/15), "stent" + aortoplastia ascendente e transversa 33,3\% (5/15), "stent" + revascularização do miocárdio 13,3\% (2/15), "stent"+ bioprótese aórtica 6,66\% (1/15), "stent" + aortoplastia ascendente de David I 46,6\% (7/15). Na Tabela 2 podemos observar os tempos transoperatórios dos procedimentos realizados.

Os "stents"utilizados da Braile Biomédica apresentavam diâmetros 26 e $28 \mathrm{~mm}$, comprimento de 75,115 e $150 \mathrm{~mm}$ e sua escolha obedecia a medida do diâmetro da aorta mais $10 \%$. São confeccionados com fios de aço inoxidável em formação pantográfica e revestidos de Dacron Woven inseridos numa bainha 30Fr. O dispositivo é auto-expansível (com memória) e sua liberação dá-se pela simples mobilização da bainha.

Três pacientes apresentaram sangramento aumentado no pós-operatório imediato, sendo que um deles drenou $1450 \mathrm{ml}$ (Tabela 3 ). Todos os pacientes receberam hemoderivados e em apenas 2 (13,3\%) não foram utilizadas plaquetas na internação.

\section{RESULTADOS}

O implante dos "stents" depois da visão do(s) orifício(s) de entrada tem como dificuldade imediata a exata colocação da prótese; na maioria dos casos o orifício de entrada encontrava-se imediatamente após a emergência da artéria subclávia esquerda. O "stent" depois de retirada sua bainha não pode ser movido, altera um pouco seu comprimento e este é o ponto chave do implante. Em 14 implantes nós ficamos satisfeitos com o local da aplicação, em um houve a obstrução parcial da subclávia esquerda sem prejuízo da circulação do membro.

O paciente de número 15 faleceu com 28 dias de evolução por septicemia decorrente de infecção respiratória por germe gram negativo, originando mortalidade hospitalar de $6,6 \%$. A paciente de número 3 foi reoperada 6 meses após por desenvolvimento de aneurisma na aorta descendente distal ao "stent" com perfuração do esôfago. O aneurisma foi ressecado, o esôfago reconstruído e a paciente encontra-se em tratamento de complicações pulmonares decorrentes de asma brônquica. O paciente de número 4 foi reoperado 3 meses após com dissecção da aorta ascendente, recebeu alta depois da aortoplastia ascendente sendo acompanhado clinicamente. As complicações ocorridas nos 15 casos durante o período hospitalar podem ser vistas na Tabela 4

Os resultados das amostras sangüíneas coletadas antes da indução anestésica (A1), após o 
Pereira W M, Frota Filho J D, Sales M, Delatorre N, Leães P E, Blacher C, Lúcio E, Pereira P Q, Silveira P G, Bonamigo T P, Lucchese

F A - "Stent" auto-expansível nas dissecções da aorta tipo B. $\quad$ Rev Bras Cir Cardiovasc 1999; 14 (3): 207-14.

TABELA 2

TEMPOS TRANSOPERATÓRIOS

\begin{tabular}{lccccc}
\hline & MÍNIMO & MÁXIMO & MÉDIO & DESVIO PADRÃO & MEDIANA \\
\hline CEC & 52 & 188 & 107,47 & $\pm 41,36$ & 102 \\
Pinçamento & 0 & 173 & 55,00 & $\pm 46,28$ & 59 \\
PC & 1 & 15 & 6,13 & $\pm 4,37$ & 4 \\
PCR & 21 & 90 & 44,60 & $\pm 18,86$ & 42 \\
Aquecimento & 25 & 52 & 38,93 & $\pm 8,48$ & 40 \\
\hline
\end{tabular}

Tempos em minutos

TABELA 3

\begin{tabular}{|c|c|c|c|c|c|}
\hline \multicolumn{6}{|c|}{ SANGRAMENTO E REPOSIÇÃO SANGÜÍNEA } \\
\hline & MÍNIMO & MÁXIMO & MÉDIO & DESVIO PADRÃO & MEDIANA \\
\hline Sangramento Transop.* & 250 & 1500 & 774,67 & $\pm 429,60$ & 650 \\
\hline Sangramento Pós-op.* & 100 & 1450 & 611,33 & $\pm 394,62$ & 590 \\
\hline Plasma* & 180 & 400 & 285,33 & $\pm 93,03$ & 300 \\
\hline Glóbulos* & 300 & 1200 & 757,33 & $\pm 250,33$ & 900 \\
\hline Plaquetas ${ }^{\star *}$ & 0 & 12 & 8,27 & $\pm 3,41$ & 10 \\
\hline
\end{tabular}

* valores em mililitro; ** valores em unidades

início da CEC (A2), antes da desconexão da CEC (A3) e após a administração da protamina (A4) são vistas nas Tabelas 5 e 6 . Durante o esfriamento e o reaquecimento, a saturação é controlada pelo cateter no bulbo da veia jugular, que durante a PCR é utilizado para medir a pressão de retroperfusão. A saturação do sangue que refluiu dos vasos cervicais é controlada a cada 10 minutos por amostras colhidas nestes vasos e procura-se manter a saturação em torno de $80 \%$ com pressão de infusão < $25 \mathrm{mmHg}$.

Do grupo de pacientes que vem em acompanhamento nestes 8 meses (14), 85,7\% estão livres de eventos neste período e a probabilidade acumulada de não ter eventos é de 0,6429 em 240 dias

TABELA 4

\begin{tabular}{lcc}
\hline \multicolumn{3}{c}{ COMPLICAÇÕES PÓS-OPERATÓRIAS } \\
\hline & $\mathbf{N}$ & PERCENTAGEM \% \\
\hline Sem complicações & 6 & $40,0 \%$ \\
Infecção Respiratória & 4 & $26,6 \%$ \\
Sangramento & 3 & $20,0 \%$ \\
Mediastinite & 1 & $6,6 \%$ \\
Insuficiência Renal Aguda & 1 & $6,6 \%$ \\
Insuficiência Aórtica & 1 & $6,6 \%$ \\
Paraparesia & 1 & $6,6 \%$ \\
\hline
\end{tabular}

Óbito = $1(6,6 \%)$
(Gráfico 1). A curva de sobrevida mostra $93,3 \%$ dos pacientes vivos no final de 8 meses e a probabilidade acumulada de sobrevivência é de 0,9310 em 240 dias (Gráfico 2).

\section{COMENTÁRIOS}

Foi DOTTER ${ }^{(14)}$ quem introduziu o conceito do tratamento de aneurismas de aorta com próteses intraluminais percutâneas em 1969. PARODI et al.(15) apresentaram sua aplicação clínica nos aneurismas da aorta abdominal em 1991. DAKE et al. (16), em 1994, mostraram experiência com 13 aneurismas da aorta torácica com "stents" auto-expansíveis. No nosso meio os trabalhos pioneiros de BUFFOLO \& PALMA (17), PALMA et al. (18) e STOLF et al. (19) mostraram que os "stents" podem ser utilizados nos aneurismas e dissecções agudas e crônicas da aorta com segurança. A utilização da vídeo assistência ${ }^{(20)}$ é um recurso que permite avaliar a aorta e suas lesões intimais únicas ou múltiplas ajudando o cirurgião no posicionamento correto da prótese. As dúvidas quanto à expansão da parede da aorta após os implantes, devido à força centrífuga exercida pelo "stent", parece ser infundada e alguns pacientes apresentam mais de 5 anos de evolução. A perfeita integração da prótese com a parede da aorta parece ocorrer ao redor dos 180 dias (21).

A experiência do Hospital São Francisco é ini- 
Pereira W M, Frota Filho J D, Sales M, Delatorre N, Leães P E, Blacher C, Lúcio E, Pereira P Q, Silveira P G, Bonamigo T P, Lucchese F A - "Stent" auto-expansível nas dissecções da aorta tipo B. $\quad$ Rev Bras Cir Cardiovasc 1999; 14 (3): 207-14.

TABELA 5

\begin{tabular}{lcccc}
\hline \multicolumn{1}{c}{ GASOMETRIAS } & $\boldsymbol{A}$ & $\boldsymbol{A 4}$ \\
\hline $\mathrm{pH}$ & $\mathbf{A 1}$ & $\boldsymbol{A 2}$ & $7,38 \pm 0,06$ & $7,46 \pm 0,04$ \\
$\mathrm{PaCO} 2$ & $40,79 \pm 0,06$ & $7,42 \pm 0,06$ & $36,08 \pm 7,56$ & $38,53 \pm 10.88$ \\
$\mathrm{Hco3}$ & $26,24 \pm 3,06$ & $37,38 \pm 5,32$ & $21,02 \pm 4,17$ & $26,50 \pm 9,81$ \\
$\mathrm{Co} 2 \mathrm{t}$ & $27,41 \pm 3,07$ & $23,69 \pm 2,76$ & $22,61 \pm 4,74$ & $24,59 \pm 5,66$ \\
$\mathrm{~EB}$ & $2,72 \pm 2,28$ & $24,91 \pm 2,86$ & $3,81 \pm 2,78$ & $4,54 \pm 2,68$ \\
PaO2 & $180,20 \pm 122,11$ & $2,73 \pm 2,83$ & $365,82 \pm 155,79$ & $208,63 \pm 107,08$ \\
Saturação & $97,50 \pm 1,99$ & $341,21 \pm 141,61$ & $99,00 \pm 0,77$ & $98,38 \pm 1,58$ \\
\hline
\end{tabular}

$\mathrm{A} 1=$ antes da indução anestésica, $\mathrm{A} 2=$ após início da CEC, $\mathrm{A} 3=$ antes da saída de CEC, A4= após a administração de protamina

TABELA 6

ELETRÓLITOS, HEMATÓCRITO, HEMOGLOBINA E GLICEMIA

\begin{tabular}{lcccc}
\hline & $\boldsymbol{A 1}$ & $\boldsymbol{A 2}$ & $\boldsymbol{A 3}$ & $\boldsymbol{A 4}$ \\
\hline Hematócrito & $36,60 \pm 5,39$ & $32,00 \pm 3,42$ & $29,30 \pm 3,35$ & $30,88 \pm 2,57$ \\
Hemoglobina & $11,92 \pm 1,88$ & $10,02 \pm 2,00$ & $9,39 \pm 0,94$ & $10,00 \pm 0,95$ \\
$\mathrm{Na}$ & $137,08 \pm 3,32$ & $137,75 \pm 2,55$ & $137,64 \pm 3,31$ & $137,86 \pm 4,12$ \\
$\mathrm{~K}$ & $3,81 \pm 0,44$ & $3,78 \pm 0,47$ & $3,64 \pm 0,84$ & $3,71 \pm 0,67$ \\
Glicemia & $111,36 \pm 13,75$ & $118,75 \pm 17,89$ & $197,63 \pm 67,97$ & $190,11 \pm 67,52$ \\
\hline
\end{tabular}

GRÁFICO 1

CURVA DE EVENTOS

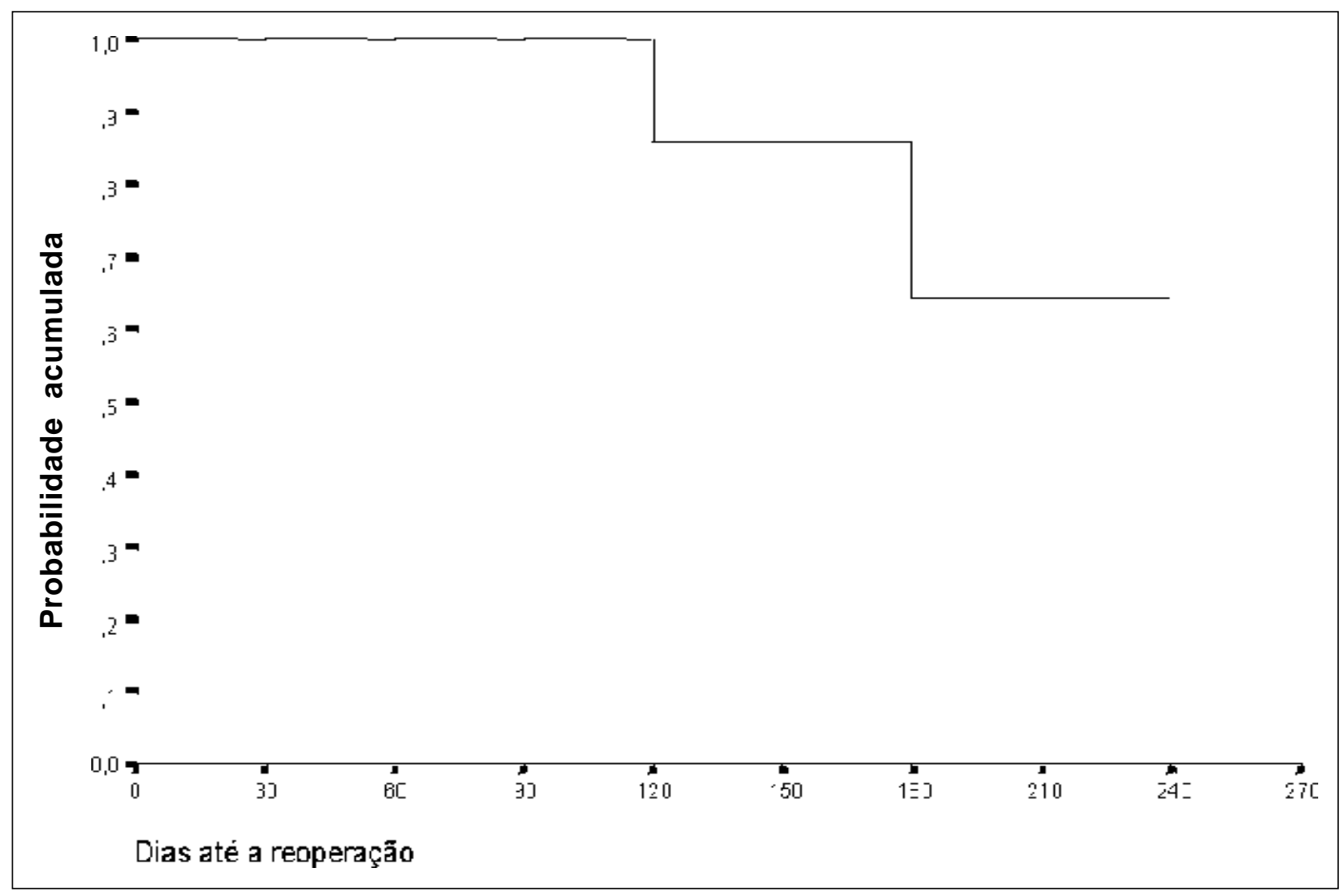


GRÁFICO 2

CURVA DE SOBREVIVÊNCIA

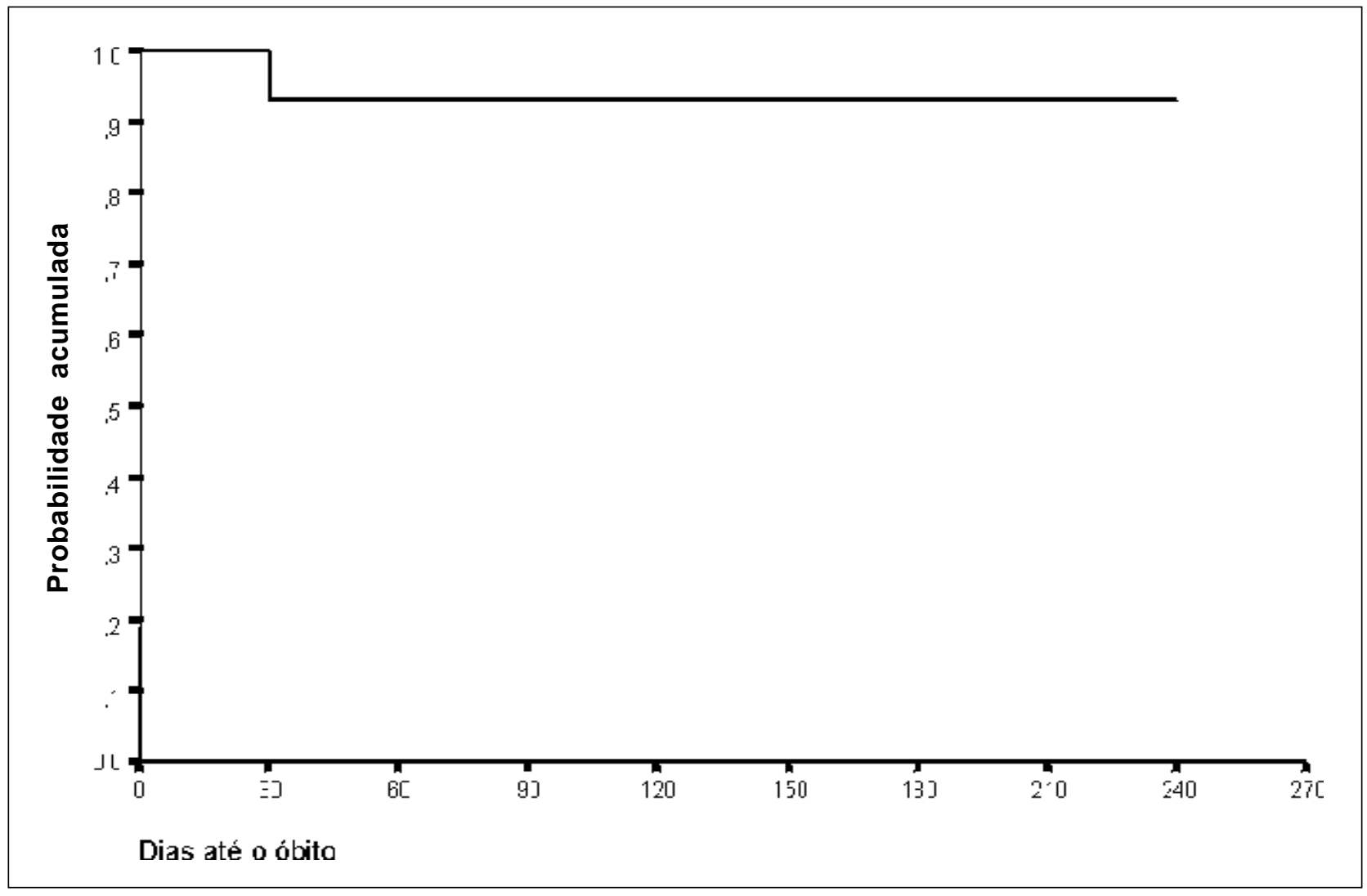

cial e não podemos tirar conclusões definitivas com um número reduzido de casos. Alguns dados já apresentam relevância e devem ser mencionados. Durante o ano de 1998, 10 pacientes internaram com diagnóstico de dissecção aguda da aorta tipo $B$ e receberam tratamento clínico intensivo (dp/dt). A mortalidade hospitalar deste grupo foi de 30\% (3/ 10), 2 pacientes foram operados no período de 10 meses com expansão da aorta. Em comparação, a mortalidade do grupo cirúrgico foi $6,6 \%$, o que é aceitável para esta lesão, pois 10 pacientes apresentavam dissecções agudas e somente em 33,3\% o implante do "stent" foi procedimento isolado. Em 7 (46,6\%) pacientes encontramos dissecção retrógrada com comprometimento da valva aórtica e a aortoplastia ascendente foi realizada aumentando o tempo e os riscos dos procedimentos. Três pacientes apresentaram distúrbios de coagulação e não necessitaram reoperações. As complicações pós-operatórias são as esperadas para este tipo de operação (tempo de intubação orotraqueal médio $=39,53 \pm 46,27$ horas, tempo de internação $=17,00 \pm 12,13$ dias).

Concluindo, podemos afirmar que a técnica de introdução dos "stents" intraluminais auto-expan- síveis é promissora, pode ser realizada com mortalidade baixa, facilita o procedimento e permite diminuir as complicações cirúrgicas transoperatórias. A morbidade dos pacientes ainda permanece a mesma porque o procedimento é invasivo, a CEC é longa e seus efeitos contribuem para isto. Talvez com o desenvolvimento dos "stents" e a introdução percutânea femoral diminua a agressão do implante reduzindo a morbidade, porém a indicação pela aorta transversa com CEC vai permanecer em casos com associação de lesões, dissecções retrógradas, entre outras. Podemos pensar, também, no uso profilático do "stent" na aorta descendente nos pacientes com dissecções agudas do tipo $\mathrm{A}$ durante as operações da aorta ascendente, prevenindo a formação de aneurismas torácicos posteriores.

\section{AGRADECIMENTO}

Os autores agredecem à srta. Vânia N. Hirakata, pela realização da análise estatística e à srta. Rachel M. Bevilácqua, pela datilografia e versão para o inglês. 
Pereira W M, Frota Filho J D, Sales M, Delatorre N, Leães P E, Blacher C, Lúcio E, Pereira P Q, Silveira P G, Bonamigo T P, Lucchese F A - "Stent" auto-expansível nas dissecções da aorta tipo B. $\quad$ Rev Bras Cir Cardiovasc 1999; 14 (3): 207-14.

RBCCV 44205-462

Pereira W M, Frota Filho J D, Sales M, Delatorre N, Leães P E, Blacher C, Lúcio E, Pereira P Q, Silveira P G, Bonamigo T P, Lucchese F A - Self-expanding stent in type B dissections of the aorta. Rev Bras Cir Cardiovasc 1999; 14 (3): 207-14.

ABSTRACT: The clinical treatment of acute type B aortic dissection has a mortality of about $25 \%$, therefore less than surgical mortality. The surgical treatment of chronic dissections also produces a high morbidity and mortality. The use of self-expanding endovascular stents offers a new alternative for the treatment of this disease. From April to December 1998, 15 endovascular stent grafts were implanted, 10 in acute dissections and 5 in chronic aneurysms. Ages ranged from 48 to 75 years (mean $=60.53 \pm 9.73$ years), with $66.6 \%$ males. The patients were submitted to medium sternotomy, extracorporeal circulation (ECC), with deep hipothermia $\left(18^{\circ}-20^{\circ} \mathrm{C}\right)$, total circulatory arrest $(\mathrm{TCA})$, and retrograde cerebral perfusion $(\mathrm{RCP})$. The transverse aorta was incised and the stent was implanted in the descending proximal aorta with the aid of aortoscopy. The times of ECC, aortic clamping, TCA, RCP, rewarming, mechanic ventilation, hospitalization, trans and post-operative bleeding, blood replacement, arterial samples, event curve and survival curve were analysed. The hospital mortality ( 30 days) was $6.6 \%$; two patients were reoperated 3 and 6 months after surgery with aortic ascending dissection and new distal aneurysm to the stent, 14 have been followed up from 1 to 8 months post-operative, $85.7 \%$ are free of events with a survival curve of $93.1 \%$ (240 days). We conclude that the self-expanding intraluminal stents implant presented a lower mortality during the acute stage of the disease $(6.6 \%)$ compared to our previous experience with clinical treatment (30\%). In spite of the small sample the procedure seems to be promising and needs more follow up.

DESCRIPTORS: Aortic aneurysm, surgery. Dissecting aneurysm, surgery. Stents.

\section{REFERÊNCIAS BIBLIOGRÁFICAS}

1 Wheat M W Jr, Palmer R F, Bartley T D, Seelman R C - Treatment of dissecting aneurysms of the aorta without surgery. J Thorac Cardiovasc Surg 1965; 50: 364-73.

2 Gurin D, Bulmer J W, Derby R - Dissecting aneurysm of the aorta: diagnosis and operative relief of acute arterial occlusion due to this cause. NY State $\mathrm{J} \mathrm{Med}$ 1935; 34: 1200-2.

3 Elefteriades J A, Hartleroad J, Gusberg R J et al. - Longterm experience with descending aortic dissection: the complication-specific approach. Ann Thorac Surg 1992; 53: 11-21.

4 Carpentier A, Deloche A, Fabini J N et al. - New surgical approach to aortic dissection: flow reversal and thromboexclusion. J Thorac Cardiovasc Surg 1981; 81: $659-68$

5 DeBakey M E, Cooley D A, Creech O Jr - Surgical considerations of dissecting aneurysm of the aorta. Ann Surg 1955; 142: 586-612.

6 Crawford E S, Walker S J, Salwa A S, Mormann N A Graft replacement of aneurysm in descending thoracic aorta: results without bypass or shunting. Surgery 1981; 89: 73-85.

7 Doroghazi R M, Stater E E, DeSanctis R W, Buckley M J, Austen W G, Rosenthal S - Long-term survival of patients with treated aortic dissections. J Am Coll Cardiol 1984; 3: 1026-34.
8 Glower D D, Fann J I, Speier R $\mathrm{H}$ et al. - Comparison of medical and surgical therapy for uncomplicated descending aortic dissection. Circulation 1990; 82 (5 suppl): IV 39-46.

9 Borst H G, Frank G, Schaps D - Treatment of extensive aortic aneurysms by a new multiple-stage approach. J Thorac Cardiovasc Surg 1988; 95: 11-3.

10 Guilmet D, Bachet J, Goudot B et al. - Use of biological glue in acute aortic dissection: preliminary clinical results with a new surgical technique. J Thorac Cardiovasc Surg 1979; 77: 516-21.

11 Abiasa S G G, Ghosh S C, Grana V P - Use of a ringed intraluminal graft in the surgical treatment of dissecting aneurysms of the thoracic aorta: a new technique. $J$ Thorac Cardiovasc Surg 1978; 76: 390-6.

12 Lemole G M, Strong M D, Spagna P M, Karmilowicz N $P$ - Improved results for dissecting aneurysms: intraluminal sutureless prosthesis. J Thorac Cardiovasc Surg 1982; 83: 249-55.

13 Berger R L, Romero L, Chaudhry A G, Dobnik D B Graft replacement of the thoracic aorta with a sutureless technique. Ann Thorac Surg 1983; 35: 231-9.

14 Dotter C T-Transluminally - placed coilspring endarterial tube grafts: long-term patency in canine popliteal artery. Invest Radiol 1969; 4: 329-32.

15 Parodi J C, Palma J H, Barone H D - Transfemoral intraluminal graft implantation for abdominal aortic aneurysms. Ann Vasc Surg 1991; 5: 491-9. 
16 Dake M D, Miller D C, Semba C P, Mitchell R S, Walker $P$ J, Liddel R P - Transluminal placement of endovascular stent-grafts for the treatment of descending thoracic aortic aneurysms. N Engl J Med 1994; 331: 1729-34.

17 Buffolo $E$ \& Palma H - Surgical treatment of type B dissecting aneurysms: what is new? Arch Chir Thorac Cardiovasc 1997; 19: 171-2.

18 Palma J H, Almeida D, Carvalho A C, Geisthövel N, Buffolo E - Utilização de endoprótese expansível ("stent") introduzida através da artéria femoral para tratamento da dissecção da aorta descendente. Rev Bras Cir Cardiovasc 1997; 12: 372-6.
19 Stolf N A G, Pêgo-Fernandes P M, Souza L R et al. Uso da prótese endovascular auto-expansível para tratamento das doenças da aorta torácica descendente. Rev Bras Cir Cardiovasc 1998; 13: 124-30.

20 Palma J H, Geisthövel N, Brasil L A, Ferrari A Jr., Carvalho A C, Buffolo $E$ - Tratamento de aneurismas da parte torácica da aorta pela introdução de "stents"sob visão endoscópica. Rev Bras Cir Cardiovasc 1998; 13: 8-12.

21 Paula I A M, Palma J H, Branco J N R et al. - Utilização de endoprótese auto expansível ("stent") posicionada na aorta torácica do cão. Rev Bras Cir Cardiovasc 1997; 12: 274-7. 